\title{
Students' Achievements in Solving Authentic Tasks with 3D Dynamic Sub-Microscopic Animations About Specific States of Water and their Transition
}

\author{
Miha Slapničar ${ }^{\star}$, Valerija Tompa, Saša A. Glažar, Iztok Devetak \\ and Jerneja Pavlin*
}

University of Ljubljana, Faculty of Education, Kardeljeva pl. 16, 1000 Ljubljana

*Corresponding authors: E-mails: miha.slapnicar@pef.uni-lj.si and jerneja.pavlin@pef.uni-lj.si

Received: 02-13-2020

\begin{abstract}
This paper aims to identify differences in the justification of the selection of 3D dynamic submicroscopic-representation (SMR) of the solid and liquid states of water, as well as the freezing of water presented in selected authentic tasks. According to students' achievements in solving these tasks at different levels of education, their explanations were identified. To explain in greater detail how students attempted to solve the authentic tasks, an eye-tracking method was used to identify the differences in the total fixation durations on specific areas of interest at the specific SMRs between successful and unsuccessful students in three age groups. A total of 79 students participated in this research. The data were collected with a structured interview conducted with students when solving three authentic tasks displayed on the computer screen. The tasks comprise text (as problem and questions), macro-images (photos of the phenomena) and SMRs of the phenomena. The eye-tracker was also used to measure the students' gaze fixations at the particular area of interest. The results show that successful students' justifications for a correct SMR include macroscopic and sub-microscopic representations of the chosen concepts. Along different stages of education, the selection success increases and sufficient justifications comprise the sub-microscopic level. It could be concluded that there are mostly no significant differences between successful and unsuccessful students within the same age group in the total fixation duration at the correct SMR. Further studies are needed to investigate the information-processing strategies between high and low achievers in solving various authentic tasks comprising SMRs and those that integrate all three levels of the representation of chemical concepts.
\end{abstract}

Keywords: States of water; freezing of water; authentic tasks; 3D dynamic SMR; eye tracking.

\section{Introduction}

Most chemical concepts are comprehended as abstract for teaching and learning because they can be represented on three different levels of representation: macroscopic, sub-microscopic, and symbolic. The teaching and learning of chemical concepts can be facilitated by context-based chemistry approaches that usually start from contexts (topics, questions) that are close to students' everyday life (authentic context). These approaches increase students' interest, activate their pre-knowledge on certain topics and offer situations in which newly developed knowledge can be applied and linked to basic concepts. ${ }^{1}$ Several authors have taken this into account when designing activities and tasks for students. ${ }^{2-5}$

However, facilitating the understanding of the specific level of representation of chemical concepts is related to the use of different visualisation tools. ${ }^{6}$ Therefore, teachers should pay more attention to the representation of structures of different substances at the sub-microscopic level so that students can develop an adequate understanding of specific chemical concepts. ${ }^{7}$ For visualisation at the sub-microscopic level, teachers could use static and dynamic $2 \mathrm{D}$ or $3 \mathrm{D}$ submicro-representations. ${ }^{89}$ However, some researchers ${ }^{10}$ have reported that students using $3 \mathrm{D}$ dynamic representations constructed a better understanding of the chemical concepts than students using static 3D representations did, while other researchers ${ }^{11}$ have reported that 3D representations help students improve incomplete understandings of the concepts and influence the construction of more complete concepts.

For an adequate understanding of the chemical concept, students must integrate all three levels of chemical concept simultaneously: the macroscopic, the sub-micro- 
scopic, and the symbolic. ${ }^{12}$ Many studies have shown that students at all levels of education have problems in interpreting and applying SMRs., ${ }^{93,14}$ These difficulties indicate a lack of connection between all three levels of the representation of the chemical concept. Researchers ${ }^{15-17}$ have found that primary school, secondary school, and university students have problems in explaining the process (represented at the macroscopic level) at the sub-microscopic level. Nevertheless, knowledge about the particulate nature of matter in different stages of education is improving. ${ }^{18}$ Based on research, ${ }^{19,20}$ primary school students have problems in understanding SMRs for states of matter and transitions between them. Sixteen-year-old students achieved higher scores in tasks about states of water when concepts regarding the gaseous state of water at the sub-microscopic level were included. ${ }^{21,22}$

It is reported that most students can explain particle motion in the liquid and solid states of matter. ${ }^{23,24} \mathrm{Stu}-$ dents aged 10 to 12 years have problems in applying particle theory to justify everyday events. Even if the students had previous theoretical knowledge about the particulate nature of matter, problems with explaining everyday events or using it to explain observed phenomena were common. ${ }^{25}$ Other researchers ${ }^{26}$ have stated that the students were unable to transfer the obtained knowledge about the particulate nature of matter to situations in everyday life. Students have problems explaining events (based on particle theory) that are related to physical changes, even if they have formed adequate particle conceptions. Teachers should use the particulate nature of matter to explain events in everyday life, which enables learning and facilitates the conceptual understanding of particle theory. ${ }^{24}$ Difficulties in the conceptual understanding of state changes have been reported in recent decades. ${ }^{27}$ However, the representation of chemical concepts using dynamic SMRs has an impact on improving students' understanding of the particulate nature of matter, ${ }^{28}$ e.g., motion ${ }^{29-32}$ and particle arrangement. ${ }^{33-35}$

The process of an individual's solving a task can be identified with eye-tracking because cognitive information processing is related to eye movements, which are used as an observable measure of visual attention. ${ }^{36-38}$ Eye-tracking studies have shown that unsuccessful task solvers have had difficulty distinguishing between relevant and irrelevant factors and in focusing on relevant factors to solve the task. Success in selecting information is crucial for successful task solving, ${ }^{39}$ and it is similar to the observation of 3D-SMRs. ${ }^{40}$ Which information is processed by the cognitive system is indicated by fixations, ${ }^{41}$ which are periods of eye stability. The eyes can only be in a stable condition for a limited time (100-500 ms). ${ }^{36,41,42}$ The most commonly used measure of eye movement is fixation duration, including a variable total fixation duration (TFD). ${ }^{42,43}$ Fixation duration measures the duration of each fixation within an area of interest (AOI). ${ }^{37,44}$ Longer fixation durations indicate the greater complexity of visual material. ${ }^{45}$ The duration of the fixation on the individual components of a display can be used to identify the AOIs. Fixation duration also indicates the time in which the information is processed. ${ }^{37} \mathrm{~A}$ longer fixation time indicates a deeper and more complex processing of the information. ${ }^{46}$

\section{Research Problem and Research Questions}

The research results ${ }^{47}$ showed an improvement in the knowledge of the states of matter at the sub-microscopic level through years of schooling. Based on research findings, primary school students have problems understanding SMRs for states of matter and transitions between them. ${ }^{19,20}$ Unsuccessful problem-solvers had difficulty in distinguishing between relevant and irrelevant factors and in focusing on the relevant factors to solve the scientific task. Success in selecting information is crucial for successful task solving. ${ }^{39}$ From the literature presented in the introduction, it is evident that difficulties in explaining the particular nature of different states of water are found among students on different stages of education.

The objectives of the research were to determine whether successful and unsuccessful students' justifications at different stages of education and aged 12 years (primary school), 16 years (upper secondary school) and 23 years (university education) differ and to identify whether successful students fix their gaze for longer times on the correct 3D-SMR than non-successful students do when solving the tasks. Two research questions were set in the research:

RQ 1: How do successful and unsuccessful students of different age groups $(12,16$, and 23 years) differ in the justifying of the selection of 3D dynamic SMRs (for the solid and liquid states of water and the freezing of water)?

RQ 2: How do successful and unsuccessful students of different age groups $(12,16$, and 23 years) differ in TFD on AOI with 3D dynamic SMRs in authentic tasks, including the solid and liquid states of water and the freezing of water?

\section{Methods}

A quantitative non-experimental research approach with descriptive methods was used.

\section{1. Participants}

A non-random, convenience sample of participants was formed from a mixed urban population, including seventy-nine Slovenian students from three different age groups. The students came from the Ljubljana region and voluntarily participated in the research. The first group included thirty students who attended the seventh grade of primary school $(M d n=12.0$ years, $I Q R=0.43$ years $)$. The 
participants of the second group $(N=29)$ attended the first year of upper secondary school $(M d n=16.0$ years, $I Q R=1.0$ years). The third group consisted of 20 students (future teachers) of the double-majors study programme of chemistry and biology/physics from the Faculty of Education of the University of Ljubljana ( $M d n=23.0$ years, $I Q R=2.0$ years $)$.

The approval for primary and upper secondary students was obtained from school authorities, teachers, and parents/caregivers, according to the Ethics Committee for Pedagogy Research of the Faculty of Education of the University of Ljubljana. All participants had normal or corrected-to-normal vision, and all were competent readers. To ensure anonymity, each student was assigned a code consisting of the letter ' $S$ ' with the number of the age group and a student number (e.g., S1_7).

The group of successful students included students who selected the correct 3D dynamic SMR for a particular state of water or freezing of water and gave the correct justifications for their decisions, while the group of unsuccessful students included students who were unsuccessful in selecting and/or justifying the selection of a correct 3D dynamic SMR.

\section{2. Instruments}

The problem set consisted of three authentic tasks. These specific tasks are three of eleven authentic science tasks that were studied from different aspects in the Slovenian Research Agency project entitled 'Explaining effec- tive and efficient problem solving of the triplet relationship in science concepts representations'. The starting point for the selection of ideas for curriculum content for the preparation of tasks was made by the review of TIMMS (Trends in International Mathematics and Science Study), the PISA Programme for International Student Assessment, and the tasks of the Slovenian national external assessment for chemistry and physics. The group of the project designed authentic context-based tasks, including 3D dynamic SMRs of chemistry concepts. The 3D dynamic SMRs were designed by science educators, as well as the authors of this paper, and, according to their developed ideas, the computer specialist completed them. The 3D dynamic SMRs were developed only for this research. The time in which the participants looked at them was not limited. When the participants needed more time to solve the tasks, the animations started again from the beginning. However, the participants did not have the possibility of controlling the animations. The text of the tasks was in the Slovenian language. For the purpose of this paper, the task texts were translated into English (see Figures 1-3).

Task 1 (Figure 1) includes macroscopic and sub-microscopic levels of representation for the solid state of water, Task 2 for the liquid state of water, and Task 3 for the freezing of water. Each task was presented by displaying a screen image (slide) in the PowerPoint presentation. Task 1 and Task 2 each consisted of two slides.

Task 1 included a photo of an iceberg, three 3D dynamic SMRs, and two questions related to the selection

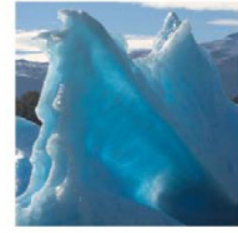

What does the photo show?

Which substance constitutes what you see in the photo?

What does the substance in the photo consist of?

In which state of matter is the substance in the photo?

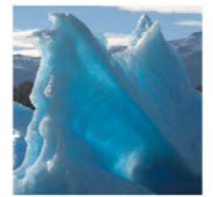

Which representation from 1 to 3 illustrates this state matter? State at least two reasons to justify your selection.

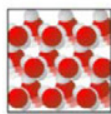

1

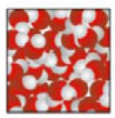

2

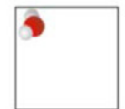

3

Figure 1. Screen images of the first authentic task, part 1 (left) and part 2 (right). (Image of an iceberg from hdwpics.com).

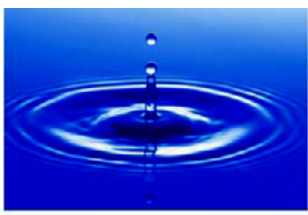

What does the photo show?

Which substance constitutes what you see in the photo?

What does the substance in the photo consist of?

In which state of matter is the substance in the photo?

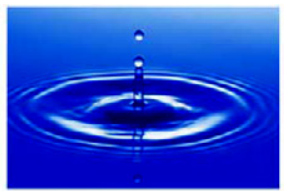

Which representation from 1 to 3 illustrates this state matter? State at least two reasons to justify your selection.

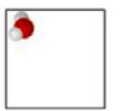

1

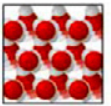

2

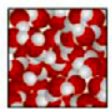

3

Figure 2. Screen images of the second authentic task, Part 1 (left) and Part 2 (right). (Image of flowing water from www.goingmobo.com). 

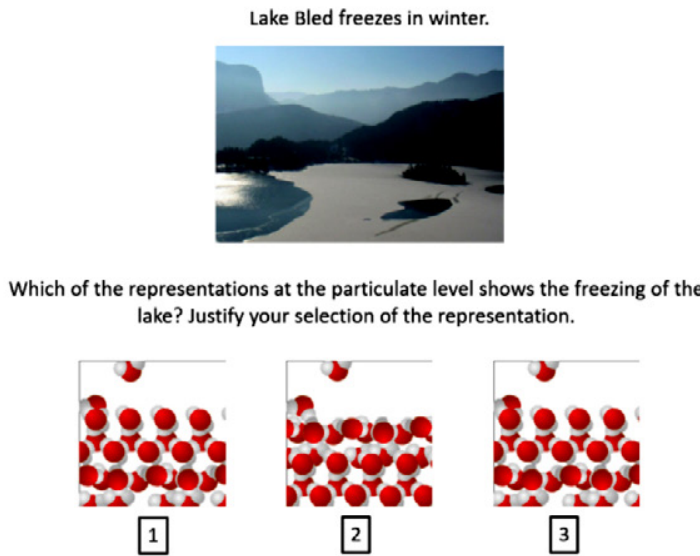

Figure 3. Screen image of the third authentic task. (Image of lake Bled from www.wikipedia.org). All SMRs represented the movement of water molecules in three different states of matter. All SMRs represented the correct movement and arrangement of particles (water molecules) in the gaseous state of water (on the top of SMR). The correct one is SMR 1 representing the liquid state in the lower part, the solid state in the middle part of the SMR, and the gaseous state in the upper part. SMR 2 did not represent the arrangement of the particles in the correct order (solid state in the lower part, liquid state in the middle part of the SMR, and gaseous state in the upper). SMR 3 is incorrect because particles do not move in the solid state of water.

and justification of the selected sub-micro-representation. Task 2 (Figure 2) consists of a photo of liquid water, three 3D dynamic SMRs, and two questions related to the selection and justification of the selected SMR. The 3D dynamic SMRs in Tasks 1 and 2 represented the correct arrangement and movement of particles in all three states of water (solid, liquid and gaseous state) in a different order. Task 3 (Figure 3) included a photo of partially frozen Lake Bled, two questions (to select and explain selected 3D sub-micro-representation) and three animations that could represent a process of water freezing.

\section{3 Research Design}

To determine the time required by successful and unsuccessful students for a certain AOI (3D dynamic SMRs for the solid, liquid state of water and freezing of water), TFDs were measured with eye-tracking. 'Fixations' refer to maintaining one's gaze on a specific AOI, while 'saccades' refer to rapid eye movements from one AOI to another. ${ }^{48}$ The identification of saccades/fixations is based on the motion of gaze during each collected sample. If both the velocity and acceleration threshold (in our case: 30 degrees per second and 8000 degrees per second squared) or are exceeded, a saccade begins; otherwise, the sample was labelled as a fixation. The screen-based EyeLink 1000 (35 mm lens, horizontal orientation) eye tracker apparatus and associated software (Experiment Builder for preparation of the experiment and a connection to EyeLink; Data Viewer for data acquisition and basic analysis) for recordings and analyses of students' eye movements when solving authentic tasks were used. Data were collected from the right eye (monocular data collection following corneal reflection and student responses) at $500 \mathrm{~Hz}^{49}$

The data were collected using the eye-tracking method in the laboratory of the Department of Psychology, of the Faculty of Arts, of the University of Ljubljana. The data collection was performed between November 2017 and January 2018. Before the individual testing with the eye tracker, each student was informed about the eye-tracking method, the purpose of the research, and their role in it. During testing with the eye tracker, a student sat in the front of the computer screen with chin and forehead held on a special head-supporting stand, which enabled the optimal measurement, recording and stability of the head and recordings. The distance between the participants' eyes and the computer screen was approximately 60 centimetres. After calibrating and validating the eye tracker using a nine-point algorithm, the student solved the tasks and gave the answers to the tester (structured interview), who transcribed them. The tasks were represented in the form of slides in a PowerPoint presentation. When the student solved the task presented on a slide, the tester switched to another slide (task). ${ }^{50}$

A basic analysis of the collected eye movement data was performed in the Data Viewer software. Further data analysis was conducted in the Statistical Package for Social Sciences (SPSS), version 22. The participants of all three age groups (12-, 16-, and 23-year-old students) were divided into successful and unsuccessful groups based on their successful justification together with the selection of the correct 3D dynamic SMR for the liquid and solid states of water and the freezing of water, as well as the reasons for their selection. The students' justifications (written down by the tester) were read several times by two authors independently, identifying and coding the most important meanings concerning the level of the chemical concept representations and correctness of the justification. The authors then met to compare and confirm the results. Any disagreements were resolved by discussion between the authors. The planned recourse to the third author for arbitration did not prove necessary. 
The mean values of the TFDs were described by a median $(M d n)$ and an interquartile range (IQR) for the specific 3D SMR. The distribution of data was non-normal, and the sample was small. Therefore, the Mann-Whitney $U$ and Kruskal-Wallis non-parametric tests were used to explain the relationship between the (un)successfully solved authentic task, including SMRs, and TFD on AOIs with SMRs. Statistical hypotheses were tested at a 5\% alpha error rate. To describe whether the effects have a relevant magnitude, the effect size measure eta squared $\eta^{2}$ was used to describe the strength of a phenomenon. Benchmarks for effects size are small (0.01), medium (0.06), and large $(0.14) .51,52$

\section{Results and Discussion}

The results are presented according to the research questions.

\section{1. Students' Achievements in Justifications Altogether with the Selection of SMR}

Research Question 1 focused on the differences between successful and unsuccessful students in three age groups in the justification of selected 3D dynamic SMRs for the solid and liquid state of water or the freezing of water.

The results showed that all students in Groups 2 and 3 chose the correct SMR for the solid and liquid state of water, while one student in Group 1 chose the incorrect SMR for the solid state of water and two of them chose the incorrect SMR for the liquid state of water; $23.33 \%$ of the students in Group 1, 58.62\% in Group 2, and $75.00 \%$ in Group 3 chose the correct 3D dynamic SMR for the freezing of water.

Table 1 presents the relative frequencies for students' achievements in justifications of the selected SMS in three tasks related to the solid and liquid state of water or the freezing of water. It is evident that the percentage of successful students' justification for the correct SMR for the solid state of water is increasing according to the stage of education from $10.00 \%$ in Group 1 to $20.00 \%$ in Group 3 . In Task 2 , on the liquid state of water, the ability to correctly justify the choice rose from $17.24 \%$ to $55.00 \%$ according to the years of schooling. The relative frequencies of suc- cessful students related to the task in water freezing increased among the years of schooling from $13.33 \%$ in Group 1 to $40.00 \%$ in Group 3. The results are coherent with researchers ${ }^{18}$ who noted that knowledge about the particulate nature of matter improves according to the stages of education. Other researchers ${ }^{19,20,48}$ have also argued about improved knowledge among the stages of education.

The level at which the justification of selected SMR (sub-microscopic, macroscopic, a combination of both levels) was argued is shown in Table 2 by absolute frequencies of justifications at the specific level of representation of chemical concepts in Tasks 1 (solid state of water), 2 (liquid state of water) and 3 (freezing of water).

The majority $(70.00 \%)$ of successful and unsuccessful students in Group 1 justified their selection for the SMR of the solid state of water (Task 1) at the macroscopic level and a combination of macroscopic and sub-microscopic levels, while most $(70.00 \%)$ successful and unsuccessful students in Group 3 justified their selection at the sub-microscopic level. It is evident that the majority of successful and unsuccessful students in all three groups listed the justifications for selecting the SMR for the liquid state of water (Task 2) at the macroscopic and sub-microscopic levels, except for the unsuccessful students in Group 3, who gave the same number of justifications at the sub-microscopic or macroscopic and sub-microscopic levels.

Successful and unsuccessful students in Group 1 explained the majority of the justifications in Task 3 (freezing of water) at the macroscopic level. Most of the successful and unsuccessful students of Group 2 discussed a selection of a correct SMR at the macroscopic and sub-microscopic levels. Successful students in Group 3 argued about the selection of an SMR for freezing of water at the macroscopic and sub-microscopic levels or at the macroscopic level, while unsuccessful students in Group 3 argued at the macroscopic and sub-microscopic levels.

This is shown by examples of justifications for Task 3 (freezing of water) that were identified as incorrect. They are listed below by age group.

Examples of incorrect justification of students of Group 1.

S1_3: The ice surface is at rest, and the water underneath moves normally.

S1_8: The ice does not freeze everywhere. It only freezes on the surface. Water vapour still evaporates.

Table 1. Relative frequencies of successful and unsuccessful students at solving tasks on solid (Task 1), liquid state of water (Task 2 ) and freezing of water (Task 3).

\begin{tabular}{lccccccccc}
\hline & \multicolumn{3}{c}{ Task 1: Solid state of water } & \multicolumn{3}{c}{ Task 2: Liquid state of water } & \multicolumn{3}{c}{ Task 3: Freezing of water } \\
\hline Group of students & 1 & 2 & 3 & 1 & 2 & 3 & 1 & 2 \\
Successful (f\%) & 10.00 & 13.79 & 20.00 & 17.24 & 50.00 & 55.00 & 13.33 & 31.03 & 40.00 \\
Unsuccessful (f\%) & 90.00 & 86.21 & 80.00 & 82.76 & 50.00 & 45.00 & 86.67 & 68.97 & 60.00 \\
\hline
\end{tabular}

Group 1: Students aged 12. Group 2: Students aged 16. Group 3: Students aged 23. 
S1_17: The layer is freezing, and not all the particles are moving. Some particles are at rest.

S1_23: Because the lake above is icy and solid and the particles are not moving. Below is liquid.

Examples of incorrect justification of students of Group 2.

S2_2: Because the top layer freezes. In the lower layer, the particles are still in motion (flowing water).

S2_6: The upper layer is still moving a little bit. Especially when we slide from the pressure, this part melts. The water freezes. A layer of water remains on top.

S2_11: Because there is ice on the surface, solid state. The particles do not move. Underneath, the water is in a liquid state, and the particles move.

S2_18: Because there is ice in the upper part, particles stand still; they do not move, and the lower part is liquid, particles move. This layer does not freeze.

Some examples of incorrect justification from students of Group 3.

S3_3: I chose animation number three because the ice structure on it is firmer because the molecules don't wobble. The molecules are connected to stronger forces during their movement than in the first animation. The ice is firmer in the third presentation and, therefore, does not break as fast as in the first presentation.

S3_5: What is the difference between 1 and 3? I do not see any difference. I will say 3. The top layer represents ice, the particles do not move, they are arranged.

S3_12: We have gaseous molecules at the top. In the middle, the lake is frozen, below it is running water.

S3_13: The bottom layer is liquid, and the top layer is ice. Here the particles are arranged and do not move. In the liquid state, the particles move in a disorderly fashion.

An example per age group of the correct justification is given as well.

Example of correct justification of students of Group 1.
S1_2: In this animation, water exists in three states of matter. I see this because the molecules move differently, even if they are the same. They move mainly in the gaseous state of water, then in liquid and then only around them in the solid state.

Example of correct justification of students of Group 2.

S2_19: In the first animation, the water in the lower part of the box is in a liquid state. In the middle of the box is ice, and on top is water vapour. The molecules in the water vapour move freely, in the solid state the water molecules in the liquid state of the water vibrate, there is something between them.

Example of correct justification of students of Group 3.

S3_7: 3D Animation 1 is correct. In Animation 1, we see that the water at the bottom of the window is in a liquid state, which illustrates that flowing water has a higher density than the ice above it. Above the ice or the solid state of water is the gaseous state of water or water vapour. Solid-state water molecules also oscillate in this representation of particle motion, which correctly illustrates the solid state.

As can be seen from the justifications for the selections of the SMRs, students of all age groups, including Group 3 (pre-service chemistry teachers), have problems describing the sub-microscopic level with the macroscopic level and misunderstandings within the sub-microscopic level, which is in line with research findings; ${ }^{19,20}$ primary school students have problems in understanding SMRs for states of matter and transitions between them, and most students can explain the motion of particles in the liquid and solid states of matter. ${ }^{23,24}$ It was found that the proportion of tested students who used macroscopic levels to represent the state of water decreased with age. ${ }^{48}$ Other studies ${ }^{15-17}$ have also shown that primary school, secondary school, and university students have problems explaining the process (represented at the macroscopic level) at the sub-microscopic level, as the present study shows. Stu-

Table 2. Relative frequencies of successful and unsuccessful students' arguments at a specific level of representation, $\mathrm{m}-\mathrm{macroscopic}$ level; $\mathrm{m} \& \mathrm{~s}$ - macroscopic and sub-microscopic level; s - sub-microscopic level.

\begin{tabular}{|c|c|c|c|c|c|c|c|c|c|c|}
\hline & & $\mathbf{m}(f)$ & $\begin{array}{l}\text { Group } 1 \\
\text { m \& s }(f)\end{array}$ & $\mathbf{s}(f)$ & $\mathbf{m}(f)$ & $\begin{array}{l}\text { Group } 2 \\
\text { m \& s }(f)\end{array}$ & $\mathbf{s}(\mathbf{f})$ & $\mathbf{m}(f)$ & $\begin{array}{l}\text { Group } 3 \\
\text { m \& s }(f)\end{array}$ & $\mathbf{s}(f)$ \\
\hline \multirow{3}{*}{ 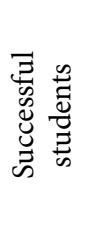 } & $\begin{array}{l}\text { Task 1: Solid } \\
\text { state of water }\end{array}$ & - & 6.67 & 3.33 & - & 6.89 & 6.89 & - & 15.00 & 40.00 \\
\hline & $\begin{array}{l}\text { Task 2: Liquid } \\
\text { state of water }\end{array}$ & - & 20.00 & - & - & 10.34 & 6.89 & - & 40.00 & 10.00 \\
\hline & $\begin{array}{c}\text { Task 3: Freezing } \\
\text { of water }\end{array}$ & 13.33 & - & - & 13.79 & 17.24 & - & 20.00 & 20.00 & - \\
\hline \multirow{3}{*}{ 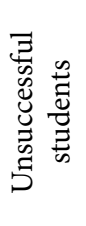 } & $\begin{array}{l}\text { Task 1: Solid } \\
\text { state of water }\end{array}$ & 13.33 & 50.00 & 26.67 & 3.45 & 48.28 & 34.48 & - & 15.00 & 30.00 \\
\hline & $\begin{array}{l}\text { Task 2: Liquid } \\
\text { state of water }\end{array}$ & 6.67 & 40.00 & 33.33 & - & 55.17 & 27.59 & - & 25.00 & 25.00 \\
\hline & $\begin{array}{c}\text { Task 3: Freezing } \\
\text { of water }\end{array}$ & 66.67 & 16.67 & 3.33 & 27.59 & 41.38 & - & 25.00 & 35.00 & - \\
\hline
\end{tabular}

Group 1: Students aged 12. Group 2: Students aged 16. Group 3: Students aged 23. 
dents often assign macroscopic properties to particulate matter, revealing their misunderstandings about the macroscopic and sub-microscopic levels of particulate matter representations..$^{21,53,54}$ In terms of teacher awareness, it is important to note that switching between the macroscopic and sub-microscopic levels is generally difficult for students. It is the teachers' task to accustom the students to sub-microscopic representations gradually and to present them with different examples so that they do not only recognise what they already know. Pre-service chemistry teachers should pay particular attention to the level of chemical concept representation so that they will be able to teach their students confidently.

\section{2. TFDs of Successful and Unsuccessful Students at AOIs with SMRs of Authentic Tasks, Including the Solid, Liquid State of Water and the Freezing of Water.}

The second research question related to the identification of differences between successful and unsuccessful students of different age groups in the TFD on AOIs, including 3D dynamic SMRs in tasks dealing with the solid, the liquid state of water and the freezing of water.

Table 3 presents Mdns and IQRs for TFD at different AOIs - 3D dynamic SMRs for successful and unsuccessful students of three age groups for Task 1 about the solid state of water. Differences in TFDs of successful and unsuccessful students of Group 1, Group 2, and Group 3 on the correct SMR 1 are not statistically significant $(U=49.000, p=$ $0.600 ; U=20.000, p=0.060 ; U=50.000, p=1.000$, respectively). However, differences in TFDs on the incorrect SMRs of successful and unsuccessful students for students from certain age groups are statistically significant only for Group 3 on AOI with the SMR $3\left(U=22.000, p=0.038, \eta^{2}\right.$
$=0.218)$. The results show that Task 1 of a solid aggregate state is well known for both successful and unsuccessful students of each age group, which is reflected in the fact that there are no statistically significant differences in the processing time of the information provided by TFD.

Differences in TFDs of successful and unsuccessful including all 79 students together on AOI with the correct SMR in Task 1 (SMR 1) were not statistically significant (successful students: $M d n=11.015, I Q R=9.055$; unsuccessful students: $M d n=13.788, I Q R=9.858 ; U=435.500$, $p=0.185$ ) as well as on the incorrect SMR 3 (successful students: $M d n=0.812, I Q R=0.969$; unsuccessful students: $M d n=1.430, I Q R=2.178 ; U=384.500, p=0.054)$. However, statistically significant differences in TFDs between all successful and unsuccessful students appear on AOI with SMR 2 (successful students: $M d n=4.530, I Q R=$ 7.462; unsuccessful students: $M d n=7.322, I Q R=8.470 ; U$ $\left.=373.000, p=0.040, \eta^{2}=0.054\right)$. The size effect is small.

Differences in TFDs of successful students regarding the age group on the AOI with the correct SMR in Task 1 were not statistically significant (Kruskal-Wallis $\chi^{2}(2)=$ 5.720, $p=0.075, \eta^{2}=0.248$ ), whereas they are statistically significant for incorrect SMRs, concretely on the AOI with SMR 2 (Kruskal-Wallis $\chi^{2}(2)=7.126, p=0.028, \eta^{2}=0.342$ ), and AOI with the SMR 3 (Kruskal-Wallis $\chi^{2}(2)=10.724, p$ $\left.=.005, \eta^{2}=0.582\right)$ (Table 3 ). This reflects the fact that successful students of all age groups observe the correct AOI for the same amount of time. It can be anticipated that this SMR is well known to the students.

Differences in the TFDs of unsuccessful students regarding the age group on the AOI with the correct SMR in Task 1 were not statistically significant (Kruskal-Wallis $\left.\chi^{2}(2)=4.451, p \leq 0.000, \eta^{2}=0.042\right)$, whereas they are statistically significant for incorrect SMRs, concretely on the AOI with SMR 2 (Kruskal-Wallis $\chi^{2}(2)=20.090, p \leq 0.001$,

Table 3. Median (Mdn) and interquartile range (IQR) of TFDs on areas of interest for successful and unsuccessful students of 3 age groups for Task 1 (solid state of water). The correct SMR is SMR 1.

\begin{tabular}{|c|c|c|c|c|c|c|c|c|}
\hline & & \multirow[b]{2}{*}{ Variable } & \multicolumn{2}{|c|}{ SMR 1} & \multicolumn{2}{|c|}{$\begin{array}{c}\text { AOI } \\
\text { SMR } 2\end{array}$} & \multicolumn{2}{|c|}{ SMR 3} \\
\hline & & & $M d n_{1}$ & $I Q R_{1}$ & $M d n_{2}$ & $I Q R_{2}$ & $M d n_{3}$ & $I Q R_{3}$ \\
\hline \multirow{2}{*}{$\begin{array}{l}\overrightarrow{0} \\
\text { Oे } \\
\stackrel{0}{0}\end{array}$} & $\begin{array}{c}\text { Successful } \\
(n=3)\end{array}$ & & 16.40 & - & 15.79 & - & 7.55 & - \\
\hline & $\begin{array}{l}\text { Unsuccessful } \\
\quad(n=27)\end{array}$ & & 16.18 & 11.62 & 13.15 & 14.03 & 2.67 & 2.72 \\
\hline \multirow{2}{*}{ 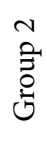 } & $\begin{array}{c}\text { Successful } \\
(n=4)\end{array}$ & & 6.60 & 5.52 & 7.15 & 16.44 & 1.36 & 1.55 \\
\hline & $\begin{array}{l}\text { Unsuccessful } \\
\quad(n=25)\end{array}$ & $T F D(s)$ & 12.49 & 9.83 & 5.46 & 4.23 & 0.93 & 0.89 \\
\hline \multirow{2}{*}{$\begin{array}{l}n \\
\text { Oे } \\
0 \\
0\end{array}$} & $\begin{array}{l}\text { Successful } \\
(n=11)\end{array}$ & & 10.82 & 8.92 & 2.53 & 3.83 & 0.38 & 0.93 \\
\hline & $\begin{array}{l}\text { Unsuccessful } \\
\quad(n=9)\end{array}$ & & 12.86 & 7.57 & 5.64 & 4.06 & 1.22 & 0.90 \\
\hline
\end{tabular}

Group 1: Students aged 12. Group 2: Students aged 16. Group 3: Students aged 23. 
$\eta^{2}=0.312$ ), and AOI with the SMR 3 (Kruskal-Wallis $\chi^{2}(2)$ $\left.=17.884, p \leq 0.001, \eta^{2}=0.274\right)$ (Table 3 ). It is evident that the correct AOI is similarly interesting for unsuccessful students of different age groups.

Table 4 shows medians and IQR for TFDs on different AOIs with 3D dynamic SMRs for successful and unsuccessful students of three age groups for Task 2 on the liquid state of water. Similar to Task 1 (solid state of water), Task 2 (including the liquid state of water) shows that there are no statistically significant differences in the TFD between successful and unsuccessful students of each age group on the correct SMR $3(U=73.000, p=1.000 ; U=$ 68.000, $p=0.674 ; U=40.000, p=0.481$ ). This might be justified by the fact that tasks containing three typical SMRs of water with only one aggregate state and that are well known to the students reflect the similar value of the TFD for successful and unsuccessful students. From this, it can be concluded that for easier and better known authentic tasks, successful and unsuccessful students within the age group have a similar processing time.

Differences in the TFDs of successful and unsuccessful 79 students on AOI with the correct SMR in Task 2 (SMR 3) were not statistically significant (successful students: $M d n=12.014, I Q R=9.601$; unsuccessful students: $M d n=13.186, I Q R=13.988 ; U=594.000, p=0.860)$ as well as on the AOI with SMR 1 (successful students: $M d n$ $=1.988, I Q R=1.622$; unsuccessful students: $M d n=2.475$, $I Q R=2.859 ; U=568.000, p=0.649)$ and on the AOI with SMR 2 (successful students: $M d n=4.504, I Q R=3.530$; unsuccessful students: $M d n=4.441, I Q R=4.454 ; U=$ 582.000, $p=0.764$ ).

Differences in TFDs of only the successful students regarding the age group on the AOI with the correct SMR in Task 1 (SMR 3) were not statistically significant (Kruskal-Wallis $\chi^{2}(2)=2.202, p=0.333$ ); it is similar on the AOI with the SMR 1 (Kruskal-Wallis $\chi^{2}(2)=1.856, p=0.395$ ).
However, statistically significant differences in TFDs of successful students regarding the age group are determined on the AOI with SMR 2 (Kruskal-Wallis $\chi^{2}(2)=$ 7.425, $\left.p=0.024, \eta^{2}=0.301\right)$ (Table 4).

Differences in TFDs of unsuccessful students regarding the age group on the AOI with the correct SMR (SMR 3 ) in task 2 were not statistically significant (Kruskal-Wallis $\left.\chi^{2}(2)=3.325, p=0.190\right)$, whereas they are statistically significant for incorrect SMRs, concretely on the AOI with SMR 1 (Kruskal-Wallis $\chi^{2}(2)=10.326, p=0.006, \eta^{2}=$ 0.151 ), and AOI with the SMR 2 (Kruskal-Wallis $\chi^{2}(2)=$ $14.518, p=0.001, \eta^{2}=0.228$ ) (Table 4 ).

Table 5 shows medians and interquartile range for TFDs on AOIs (3D dynamic SMRs) for successful and unsuccessful students of three age groups for Task 3 on the freezing of water. Differences in TFDs of successful and unsuccessful students for students from the certain age group on the correct (SMR 1) and other two incorrect SMRs were not statistically significant (SMR 1: Group 1: $U$ $=83.000, p=0.061$; Group 3: $U=141.000, p=0.015$; SMR 2: Group 1: $U=53.000, p=0.734$; Group 2: $U=78.000, p$ $=0.594$; Group 3: $U=36.000, p=0.384$; SMR 3: Group 1: $U=38.000, p=0.425$; Group 2: $U=83.000, p=0.764$; Group 3: $U=32.000, p=0.238)$. An exception appears in Group 2 on the AOI with the correct SMR $(U=141.00, p=$ $0.015, \eta^{2}=0.199$ ). The results obtained show that the interpretation of the results for the liquid aggregate state of water is highly similar to the interpretation of the results for the solid aggregate state of water, which is confirmed by the fact that the successful and unsuccessful students of each age group, individual and known SMR, are similarly interested in solving the problem.

Differences in TFDs of the successful and unsuccessful 79 students on AOI with the correct SMR in Task 3 (SMR 1) were statistically significant with large effect (successful students: $M d n=22.648, I Q R=18.018$; unsuccessful students:

Table 4. Median (Mdn) and interquartile range (IQR) of interest for successful and unsuccessful students of 3 age groups in Task 2 (liquid state of water). The correct SMR is SMR 3.

\begin{tabular}{|c|c|c|c|c|c|c|c|c|}
\hline & & \multirow[b]{2}{*}{ Variable } & \multicolumn{2}{|c|}{ SMR 1} & \multicolumn{2}{|c|}{$\begin{array}{c}\text { AOI } \\
\text { SMR } 2\end{array}$} & \multicolumn{2}{|c|}{ SMR 3} \\
\hline & & & $M d n_{1}$ & $I Q R_{1}$ & $M d n_{2}$ & $I Q R_{2}$ & $M d n_{3}$ & $I Q R_{3}$ \\
\hline \multirow{2}{*}{ 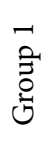 } & $\begin{array}{l}\text { Successful } \\
(n=6)\end{array}$ & & 2.30 & 3.30 & 6.17 & 5.28 & 16.85 & 13.32 \\
\hline & $\begin{array}{c}\text { Unsuccessful } \\
(n=24)\end{array}$ & & 4.21 & 6.56 & 6.20 & 4.98 & 17.05 & 16.24 \\
\hline \multirow{2}{*}{ 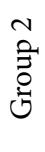 } & $\begin{array}{l}\text { Successful } \\
\quad(n=5)\end{array}$ & & 1.56 & 1.18 & 3.61 & 3.08 & 9.51 & 10.92 \\
\hline & $\begin{array}{l}\text { Unsuccessful } \\
\quad(n=24)\end{array}$ & $T F D(\mathrm{~s})$ & 1.73 & 2.18 & 3.22 & 3.88 & 9.81 & 10.66 \\
\hline \multirow{2}{*}{ 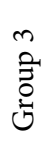 } & $\begin{array}{l}\text { Successful } \\
(n=10)\end{array}$ & & 2.28 & 2.20 & 3.59 & 2.72 & 11.47 & 8.90 \\
\hline & $\begin{array}{l}\text { Unsuccessful } \\
\quad(n=10)\end{array}$ & & 1.78 & 2.62 & 2.26 & 3.18 & 13.97 & 11.10 \\
\hline
\end{tabular}

Group 1: Students aged 12. Group 2: Students aged 16. Group 3: Students aged 23. 
$M d n=12.518, I Q R=12.481 ; U=918.000, p=0.001, \eta^{2}=$ 0.149 ); they were not statistically significant for the AOI with the SMR 2 (successful students: $M d n=6.694, I Q R=$ 6.301; unsuccessful students: $M d n=7.414, I Q R=8.076 ; U=$ 524.000, $p=0.346$ ) and AOI with the SMR 3 (successful students: $M d n=9.408, I Q R=9.218$; unsuccessful students: $M d n=13.407, I Q R=14.987 ; U=446.000, p=0.070, \eta^{2}=$ $0.041)$. Successful students spent more time on the correct SMR, which might be interpreted as successful students helping with the correct SMR when justifying the selection.

Differences in TFDs of successful students regarding the age group on the AOI with the correct SMR in Task 3 (SMR 1) and incorrect SMRs were not statistically significant (Kruskal-Wallis $\chi^{2}(2)=0.532, p=0.766$; Kruskal-Wallis $\chi^{2}(2)=1.583, p=0.453$; Kruskal-Wallis $\chi^{2}(2)=0.396, p$ $=0.820$ ) (Table 5). The result shows that successful students, regardless of age group, spend similar time with AOIs, which shows that the effort for processing the visible information of successful students is similarly high when solving the task.

Differences in TFDs of unsuccessful students regarding the age group on the AOI with the correct SMR in Task 3 were statistically significant (Kruskal-Wallis $\chi^{2}(2)=$ 9.225, $p=0.010, \eta^{2}=0.131$ ), whereas they were not statistically significant for incorrect SMRs, concretely on the AOI with SMR 2 (Kruskal-Wallis $\chi^{2}(2)=0.070, p=0.965$ ), and AOI with the SMR 3 (Kruskal-Wallis $\chi^{2}(2)=5.143, p$ $=0.076)$ (Table 5).

It can be concluded that successful students (of all age groups) spend more time with the correct SMR when justifying their choice, which leads them to correctly solve the task, while the irrelevant information on the screen image is observed for less time. Unsuccessful task-solvers have difficulty in distinguishing between relevant and irrelevant factors and in focusing on the relevant factors to solve the authentic task, which is (to some extent) consistent with the results of this research. Success in selecting information is crucial for successful task-solving, which is similar to the observation of 3D dynamic SMRs. ${ }^{39,40}$

\section{Conclusions}

The focus of the presented research was to explore and explain students' justifications for the selection of the correct SMR in solving context-based tasks on the solid and liquid states of water and the process of freezing water, which include macroscopic and sub-microscopic levels of chemical concepts, and to identify differences between successful and unsuccessful students in justifying the selection of 3D dynamic SMRs and differences in the TFDs in solving the task among students in different groups.

The first research question referred to the students' justification of the selected correct SMR in three tasks related to states of matter and the impact of the stages of education in the justifications for the decision of selecting 3D dynamic SMRs for the solid and liquid states of water or the freezing of water between successful and unsuccessful students. It is evident that along the stages of education, the percentage of correct justifications of the selected SMR of the tasks increase and the justifications in the combination of sub-microscopic and macroscopic levels are mostly dominant for students of all ages for the solid and liquid states of water. The students in Group 1 stated the majority of the justifications at the macroscopic level. In contrast, most successful students in Groups 2 and 3 mentioned the choice of an SMR for the freezing of water at the macroscopic and sub-microscopic levels.

The second set of findings is related to the identification of differences in TFDs between successful and unsuc-

Table 5. Median (Mdn) and interquartile range (IQR) of interest for successful and unsuccessful students of three age groups in Task 3 (freezing of water). The correct SMR is SMR 1.

\begin{tabular}{|c|c|c|c|c|c|c|c|c|}
\hline & & \multirow[b]{2}{*}{ Variable } & \multicolumn{2}{|c|}{ SMR 1} & \multicolumn{2}{|c|}{ AOI } & \multicolumn{2}{|c|}{ SMR 3} \\
\hline & & & $M d n_{1}$ & $I Q R_{1}$ & $M d n_{2}$ & $I Q R_{2}$ & $M d n_{3}$ & $I Q R_{3}$ \\
\hline \multirow{2}{*}{$\begin{array}{l}\overrightarrow{0} \\
\overrightarrow{0} \\
\stackrel{0}{0}\end{array}$} & $\begin{array}{l}\text { Successful } \\
\quad(n=4)\end{array}$ & & 22.51 & 29.30 & 9.46 & 9.64 & 9.93 & 13.9 \\
\hline & $\begin{array}{l}\text { Unsuccessful } \\
\qquad(n=26)\end{array}$ & & 8.53 & 10.96 & 8.75 & 9.02 & 14.44 & 13.94 \\
\hline \multirow{2}{*}{ 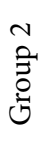 } & $\begin{array}{c}\text { Successful } \\
\quad(n=9) \\
\text { Unsuccessful }\end{array}$ & TFD (s) & 25.76 & 15.90 & 7.79 & 5.04 & 9.41 & 8.98 \\
\hline & $(n=20)$ & & 12.29 & 8.82 & 7.11 & 5.80 & 9.10 & 10.26 \\
\hline \multirow{2}{*}{ 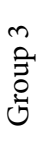 } & $\begin{array}{l}\text { Successful } \\
\quad(n=8)\end{array}$ & & 20.82 & 23.36 & 5.69 & 6.62 & 9.22 & 14.42 \\
\hline & $\begin{array}{l}\text { Unsuccessful } \\
\quad(n=12)\end{array}$ & & 19.46 & 25.44 & 7.05 & 9.94 & 18.08 & 16.06 \\
\hline
\end{tabular}

Group 1: Students aged 12. Group 2: Students aged 16. Group 3: Students aged 23. 
cessful students of the same and different age groups in solving tasks, including the solid and liquid states of water and the freezing of water. From the results of the TFDs in all tasks for the AOI with the correct SMR, it can be concluded that successful and unsuccessful students of the same age group observe SMRs for a similar amount of time while solving the task.

In justifying the choice of the correct SMR for the solid and liquid aggregate states of water, it is assumed that there are no differences between all successful and unsuccessful students, while in the case of the freezing water task, there are no differences, which indicates that easy and wellknown SMRs do not require significant differences in observation time while students are justifying them. This is not the case for SMRs that are unknown to the students and, therefore, more difficult. In this case, the differences in SMR observation time are greater. The results suggest that successful students need more time to justify the choice of the right SMR for more difficult tasks that require greater cognitive effort, which is not true for unsuccessful students whose excessive cognitive effort hinders the path to the correct justification of the choice of the correct SMR.

A comparison of successful students of different age groups shows that all of them observe SMRs a similar time while explaining the choice. From this, it can be concluded that all successful students, regardless of age group, have a similar cognitive effort to justify the choice of the correct SMR, as evidenced by the similar processing of visible information on a computer screen image.

The limitations of this research are differences in the size of the groups of successful and unsuccessful students and the criteria used to classify students into successful and unsuccessful.

Based on the research results, we can make some recommendations for chemistry or science teaching: teachers who teach chemistry and other science subjects at different stages of education should strive to formulate the justification of the chosen SMRs appropriately in their teaching by including SMRs. The justification must combine the macroscopic and sub-microscopic levels of the chemical concept representation.

For unsuccessful students, it is useful that teachers, when observing the SMRs, gradually guide students to find key facts relevant to formulating an appropriate justification.

For further research, it will be necessary to carry deeper analyses of eye-tracker measures on an unknown task, as well as more tasks that also examine the other changing states of matter, information about the level of logical thinking of the students and their visual abilities, information about the way that SMRs were presented to them during the classes, etc. We will examine how future chemistry teachers, as well as those teachers who already teach chemistry and have extensive practical experience in teaching SMRs, explain the chosen SMR orally. The comparison of the results can aid in providing guidelines for the proper training of future chemistry teachers.

\section{Acknowledgement}

This research was supported by the project 'Explaining effective and efficient problem solving of the triplet relationship in science concepts representations' (J5-6814), funded by the ARRS - Slovenian research agency.

\section{References}

1. I. Parchmann, R. Blonder, K. Broman, in: L. Leite, L. Dourado, A. S. Afonso, S. Morgado (Eds.): Contextualizing Teaching to Improve Learning the Case of Science and Geography, Nova Science Publishers, New York, United States of America, 2017, pp. 25-39.

2. K. Broman, I. Parchmann, Chem. Educ. Res. Pract. 2014, 15, 516-529. DOI:10.1039/C4RP00051J

3. J. Majer, M. Slapničar, I. Devetak, Acta Chim. Slov. 2019, 66, 659-667. DOI:10.17344/acsi.2019.5087

4. M. Slapničar, I. Devetak, S. A. Glažar, J. Pavlin, J. Balt. Sci. Edu. 2017, 16, 308-323.

5. M. Slapničar, V. Tompa, S. A. Glažar, I. Devetak, J. Balt. Sci. Edu. 2018, 17, 620-632.

6. I. Devetak: Provision of high quality scientific knowledge through submicro-representations, Ljubljana, Univerza v Ljubljani, Pedagoška fakulteta. 2012, pp. 13-16.

7. I. Devetak, M. Hajzeri, S. A. Glažar, J. Vogrinc, Acta Chim. Slov. 2010, 57, 904-911.

8. J. Trumbo, Sci. Commun. 1999, 20, 409-425. DOI: $10.1177 / 1075547099020004004$

9. H. K. Wu, J. S. Krajcik, E. Soloway, J. Res. Sci. Teach. 2001, 38, 821-842. DOI:10.1002/tea.1033

10. S. C. Chen, H. C. She, M. S. Hsiao, Comput. Human. Behav. 2015, 53, 169-180. DOI:10.1016/j.chb.2015.07.003

11. C. F. Wu, M. C. Chiang, Comput. Educ. 2013, 63, 28-42. DOI:10.1016/j.compedu.2012.11.012

12. A. H. Johnstone, Sch. Sci. Rev. 1982, 64, 377-379.

13. M. Heitzman, J. Krajcik, Urban Seventh-grader's Translations of Chemical Equations: What Parts of the Translation Process do Students Have Trouble? http://www.project2061. org/research/ccms/site.archive/documents/Translations_of_ Chemical_Equations.pdf, (assessed: December 27, 2019).

14. R. Kozma, E. Chin, J. Russell, N. Marx, J. Learn. Sci. 2000, 9, 105-143. DOI:10.1207/s15327809jls0902_1

15. E. Adadan, F. Savasci, Int. J. Sci. Educ. 2011, 34, 513-544. DOI:10.1080/09500693.2011.636084

16. K. de Berg, Chem. Educ. Res. Pract. 2012, 13, 8-16. DOI:10.1039/C1RP90056K

17. A. I. Kern, N. B. Wood, G. H. Roehrig, J. Nyachwaya, Chem. Educ. Res. Pract. 2010, 11, 165-172. DOI:10.1039/C005465H

18. D. Özalp, A. Kahveci, Chem. Educ. Res. Pract. 2015, 16, 619639. DOI:10.1039/C5RP00096C

19. I. Devetak, J. Vogrinc, S. A. Glažar, Res. Sci. Educ. 2009, 39, 157-179. DOI:10.1007/s11165-007-9077-2 
20. V. Kind, Beyond appearances: students' misconceptions about basic chemical ideas, 2nd edition, http://modeling.asu. edu/modeling/KindVanessaBarkerchem.pdf, (assessed: December 27, 2019).

21. M. L. Chiu, M. H. Chiu, C. Y. Ho, Proc. Natl. Sci. Counc. 2002, 12, 91-99.

22. I. Devetak: Explaining the latent structure of understanding submicrorepresentations in science. Ph. D. Thesis, Ljubljana: University of Ljubljana. 2005.

23. K. Adbo, K. S. Taber, Int. J. Sci. Educ. 2009, 31, 757-786. DOI:10.1080/09500690701799383

24. Y. Boz, J. Sci. Educ. Tech. 2006, 15, 203-213. DOI:10.1007/s10956-006-9003-9

25. H. Özmen, Eurasian J. Phys. Chem. Educ. 2013, 5, 81-90.

26. L. Löfgren, G. Hellden, Int. J. Sci. Educ. 2009, 31, 1631-1655. DOI:10.1080/09500690802154850

27. G. Tsitsipis, D. Stamovlasis, G. Papageorgiou, Int. J. Sci. Educ. 2010, 32, 987-1016. DOI:10.1080/09500690902893605

28. E. E. Olakanmi, J. Balt. Sci. Edu. 2015, 14, 627-640.

29. V. M. Williamson, M. R. Abraham, J. Res. Sci. Teach. 1995, 32, 521-534. DOI:10.1002/tea.3660320508

30. J. W. Russell, R. B. Kozma, T. Jones, J. Wykoff, N. Marx, J. Davis, J. Chem. Educ. 1997, 74, 330-334.

DOI:10.1021/ed074p330

31. M. J. Sanger, J. Chem. Educ. 2000, 77, 762-766.

DOI:10.1021/ed077p762

32. D. M. Bunce, D. Gabel, J. Res. Sci. Teach. 2002, 39, 911-927. DOI:10.1002/tea.10056

33. M. Barak, Y. J. Dori, Sci. Educ. 2005, 89, 117-139. DOI:10.1002/sce.20027

34. E. J. Yezierski, J. P. Birk, J. Chem. Educ. 2006, 83, 954-960. DOI:10.1021/ed083p954

35. M. B. Nakhleh, J. Chem. Educ. 1992, 69, 191-196. DOI:10.1021/ed069p191

36. S. Eivazi, R. Bednarik, Predicting problem-solving behaviour and performance levels from visual attention data, https://pdfs.semanticscholar.org/25c0/b17194ce09f600c766867e8962e4ee4f7784.pdf?_ga=2.206226385. 334794364. 1575983244- 1516362230.1550597977, (assessed: December 5, 2019).

37. K. L. Havanki, J. R. VandenPlas in: D. M. Bunce, R. S. Cole (Ed.): Tools of Chemistry Education Research, ACS Symposium Series, American Chemical Society, Washington DC, 2014, pp. 191-218.

DOI:10.1021/bk-2014-1166.ch011

38. K. Rayner, Q. J. Exp. Psychol. 2009, 62, 1457-1506.

\section{DOI:10.1080/17470210902816461}

39. M. Tsai, H. Hou, M. Lai, W. Liu, F. Yang, Comput. Educ. 2011, 58, 375-385. DOI:10.1016/j.compedu.2011.07.012

40. B. B. Koning, H. K. Tabbers, R. M. J. P. Rikers, F. Paas, Educ. Pscychol. Rev. 2009, 2, 113-140.

DOI:10.1007/s10648-009-9098-7

41. G. Underwood, R. Radach, in: G. Underwood (Ed.): Eye Guidance in Reading and Scene Perception, Elsevier Science, Oxford, UK, 1998, pp. 1-27.

DOI:10.1016/B978-008043361-5/50002-X

42. K. Holmqvist, M. Nystrom, R. Andersson, R. Dewhurst, H. Jarodzka, H. in Van de Weijer, J. (2011). Eye tracking: A comprehensive guide to methods and measures. Oxford University Press, Oxford, UK, 2011.

43. V. Ferk Savec, Š. Hrast, I. Devetak, G. Torkar, Acta Chim. Slov. 2016, 63, 864-873. DOI:10.17344/acsi.2016.2835

44. Timing guide for tobi eye trackers and eye tracking software, 2010, Tobii technology, https://www.tobiipro.com/siteassets/ tobii-pro/learn-and-support/design/eye-tracker-timing-performance/tobii-eye-tracking-timing.pdf, (assessed: December 5, 2019).

45. H. J. Green, P. Lemaire, S. Dufau, Acta Psychol. 2007, 125, 257-278. DOI:10.1016/j.actpsy.2006.08.001

46. J. Hyönä, R. F. Jr. Lorch, J. K. Kaakinen, J. Educ. Psychol. 2002, 94, 44-55. DOI:10.1037/0022-0663.94.1.44

47. M. P. Pereira, M. E. M. Pestana, Int. J. Sci. Educ. 1991, 13, 313-319. DOI:10.1080/0950069910130309

48. A. T. Duchowski, Eye tracking methodology, Springer, London, UK, 2007.

49. G. Torkar, M. Veldin, S. A. Glažar, A. Podlesek, Eurasia J. Math. Sci Tecnol. Educ. 2018, 14, 2265-2276.

DOI: $10.29333 /$ ejmste/87119

50. J. Pavlin, S. A. Glažar, M. Slapničar, I. Devetak, Chem. Educ. Res. Pract. 2019, 20, 633-649. DOI: 10.1039/c8rp00189h

51. J. Pallant, SPSS survival manual: A step by step guide to data analysis using SPSS, Allen \& Unwin, Crows Nest, Australia, 2011. DOI: $10.1039 / \mathrm{C} 8 \mathrm{RP} 00189 \mathrm{H}$

52. J. Cohen, Statistical power analysis for the behavioral sciences, Lawrence Erlbaum Associates, Hillsdale, NJ, 1988.

53. A. G. Harrison, D. F. Treagust, Sci. Educ. 2000, 84, 352-381. DOI:10.1002/(SICI)1098-237X(200005)84:3<352:: AID-SCE3 $>3.0 . \mathrm{CO} ; 2-\mathrm{J}$

54. G. Nicoll, Int. J. Sci. Educ. 2001, 23, 707-730. DOI:10.1080/09500690010025012 


\section{Povzetek}

V članku predstavljena raziskava se ukvarja z identifikacijo razlik med udeleženci raziskave, ki so uspešno oz. neuspešno utemeljili izbiro $3 \mathrm{D}$ dinamične submikroskopske predstavitve (SMR) trdnega in tekočega agregatnega stanja vode ter zmrzovanja vode. Preučevane so bile tudi razlike v času trajanja fiksacij na izbranih interesnih področjih med njimi. V raziskavi je sodelovalo 79 udeležencev treh starostnih skupin. Podatki so bili zbrani s strukturiranim intervjujem, ki je vključeval računalniške zaslonske slike treh avtentičnih nalog. Naloga je vsebovala besedilo (problem ali vprašanje), fotografijo pojava na makroskopski ravni in SMR pojava. Metoda očesnega sledilca je bila uporabljena za merjenje fiksacij med reševanjem avtentičnih nalog na določenem interesnem področju. Rezultati kažejo, da so uspešni posamezniki pri utemeljitvah vključevali predvsem makroskopske in submikroskopske predstavitve izbranega pojma. Po vertikali izobraževanja narašča uspešnost izbire in pravilnost utemeljitve prevladujoče na submikroskopski ravni. Med uspešnimi in neuspešnimi učečimi se iste starostne skupine, se po večini ne pojavijo razlike v času trajanja fiksacij na izbranem interesnem področju (pravilni SMR). Potrebne so nadaljnje raziskave, s katerimi bo preučeno procesiranje informacij uspešnih in neuspešnih učečih se, pri reševanju različnih avtentičnih nalog s SMR.

Except when otherwise noted, articles in this journal are published under the terms and conditions of the Creative Commons Attribution 4.0 International License 